\title{
Identification of salt tolerance-related genes of Lactobacillus plantarum D31 and T9 strains by genomic analysis
}

\author{
Wenting Yao ${ }^{1+}$, Lianzhi Yang ${ }^{1 \dagger}$, Zehuai Shao ${ }^{1}$, Lu Xie $^{2}$ and Lanming Chen ${ }^{1 *}$
}

\begin{abstract}
Purpose: The aim of this study was to identify salt tolerance-related genes of Lactobacillus plantarum D31 and T9 strains, isolated from Chinese traditional fermented food, by genomic analysis.

Methods: Tolerance of L. plantarum D31 and T9 strains was evaluated at different stress conditions (temperatures, acid, osmolality, and artificial gastrointestinal fluids). Draft genomes of the two strains were determined using the Illumina sequencing technique. Comparative genomic analysis and gene transcriptional analysis were performed to identify and validate the salt tolerance-related genes.

Results: Both L. plantarum D31 and T9 strains were able to withstand high osmotic pressure caused by $5.0 \% \mathrm{NaCl}$, and L. plantarum D31 even to tolerate 8.0\% NaCl. L. plantarum D31 genome contained 3,315,786 bp (44.5\% GC content) with 3106 predicted protein-encoding genes, while L. plantarum T9 contained 3,388,070 bp (44.1\% GC content) with 3223 genes. Comparative genomic analysis revealed a number of genes involved in the maintenance of intracellular ion balance, absorption or synthesis of compatible solutes, stress response, and modulation of membrane composition in L. plantarum D31 and or T9 genomes. Gene transcriptional analysis validated that most of these genes were coupled with the stress-resistance phenotypes of the two strains.

Conclusions: L. plantarum D31 and T9 strains tolerated 5.0\% NaCl, and D31 even tolerated $8.0 \% \mathrm{NaCl}$. The draft genomes of these two strains were determined, and comparative genomic analysis revealed multiple molecular coping strategies for the salt stress tolerance in L. plantarum D31 and T9 strains.
\end{abstract}

Keywords: Lactobacillus plantarum, Salt stress tolerance, Genome sequence, Comparative genomics, Gene transcription, Traditional fermented food

\section{Introduction}

Lactic acid bacteria (LAB) are generally recognized as safe food-grade microorganisms. Numerous previous studies have revealed their beneficial effects on human health, such as maintaining the balance of gastrointestinal microbial community, acting against pathogenic microorganisms, and enhancing innate and adaptive immune responses (Chen et al. 2014; Liu et al. 2018; Nazir et al. 2018). Lactobacillus plantarum is one of the most

\footnotetext{
* Correspondence: Imchen@shou.edu.cn

†'Wenting Yao and Lianzhi Yang contributed equally to this work.

'Key Laboratory of Quality and Safety Risk Assessment for Aquatic Products

on Storage and Preservation (Shanghai), China Ministry of Agriculture,

College of Food Science and Technology, Shanghai Ocean University,

Shanghai 201306, People's Republic of China

Full list of author information is available at the end of the article
}

widely applied LAB in the food industry. The bacterium is found to thrive in indigenous microbiota commonly found in fermented food (Zago et al. 2011) and can competitively inhibit pathogenic bacteria growth during fermentation (Molin 2001).

LAB chosen for commercial purposes must challenge adverse conditions encountered in industrial processes, such as heat, cold, acidity, and high concentrations of $\mathrm{NaCl}$ (Bucka-Kolendo and Sokolowska 2017). Many fermented food are made with the salt, by which osmotic stress is often a significant challenge for microorganisms surviving in fermentation processes (El-Gendy et al. 1983; Yamani et al. 1998; Prasad et al. 2003; Rao et al. 2004). Possible mechanisms of the regulation of intracellular osmotic pressure in LAB have been mentioned, 
such as (1) exclusion of $\mathrm{Na}^{+}$ion from cells, (2) accumulation of compatible solutes, and (3) changes of cell membrane composition. In the past decade, a number of LAB strains have been subjected for genome sequencing to further address their physiological functions and environmental adaptation mechanisms, along with the development of genome sequencing technologies. To date, more than 50 complete genome sequences of L. plantarum strains are available in the GenBank database (http://www.ncbi.nlm.nih.gov/genome/). Genomic diversity and versatility of L. plantarum have been reported (Siezen and van Hylckama Vlieg 2011; Jiang et al. 2018; Evanovich et al. 2019). Nevertheless, among these strains, only L. plantarum ST-III has been reported to be able to survive in De Man Rogosa and Sharp (MRS) medium with $7.5 \% \mathrm{NaCl}$ (Chen et al. 2012). A $k d p$ gene cluster encoding a high-affinity $\mathrm{K}^{+}$-transport system was identified from a 53.56-kb plasmid pST-III in L. plantarum ST-III, which was found to contribute to its viability under hyperosmotic conditions (Chen et al. 2012). Recently, Wang et al. reported that $L$. plantarum ATCC 14917 was also able to survive in the MRS medium with $6.0 \% \mathrm{NaCl}$. The expression of eleven genes were upregulated in this bacterium to respond to the salt stress, including those involved in carbohydrate metabolism, transcription and translation, fatty acid biosynthesis, and primary metabolism (Wang et al. 2016).

L. plantarum with novel functional properties is of interest to both academic institution and food industry. In our prior studies, a number of LAB strains were isolated from Chinese traditional fermented food and identified and characterized by $\mathrm{Xu}$ et al. (Xu et al. 2016). Among these, L. plantarum D31 and L. plantarum T9 strains showed high levels of antioxidant and bile salt hydrolase activities in in vitro tests (Xu et al. 2016). In this study, tolerance of these two strains to various stress conditions was further evaluated, and the resulting data showed that both L. plantarum D31 and T9 strains were able to survive in the MRS medium with $5.0 \% \mathrm{NaCl}$, and L. plantarum D31 even tolerated to $8.0 \% \mathrm{NaCl}$. Thus, draft genome sequences of these two strains were determined using the Illumina sequencing technique in order to get genomic insights into possible molecular mechanisms of the salt tolerance of $L$. plantarum.

\section{Materials and methods}

\section{L. plantarum strains and cultural conditions}

L. plantarum D31 and T9 strains, isolated from Chinese traditional fermented food Dongbei kimichi and milk tofu, respectively, have been identified and characterized in our previous research (Xu et al. 2016). In this study, these two strains were individually inoculated from our laboratory stock at $-80{ }^{\circ} \mathrm{C}$ into the MRS medium $(\mathrm{pH}$ 6.8, Beijing Land Bridge Technology, Beijing, China) and incubated at $37{ }^{\circ} \mathrm{C}$ for $24 \mathrm{~h}$ under anaerobic conditions as described previously (Xu et al. 2016). Bacterial cells were harvested by centrifugation at $4000 \mathrm{r} / \mathrm{min}$ for 10 min and washed three times using the sterile $1 \times$ phosphate-buffered saline (PBS, pH 7.0, Shanghai Sangon Biological Engineering Technology and Services Co., Ltd., Shanghai, China). Then, cell pellets were resuspended with an appropriate amount of sterile deionized water and used as the inoculum $\left(10^{7}-10^{8}\right.$ colony forming unit $(\mathrm{CFU}) / \mathrm{ml})$ in the further analyses. Cell density was determined using a multimode microplate reader (Synergy, BioTek Instruments, Winooski, VT, USA), and the $\mathrm{OD}_{600 \mathrm{~nm}}$ value was used as a related parameter for the amount of bacteria biomass (Dahroud et al. 2016).

\section{Stress conditions}

L. plantarum D31 and T9 strains were individually incubated in the MRS medium ( $\mathrm{pH}$ 6.8) at different temperatures $\left(15{ }^{\circ} \mathrm{C}, 20{ }^{\circ} \mathrm{C}, 25{ }^{\circ} \mathrm{C}, 37{ }^{\circ} \mathrm{C}\right.$, and $\left.45{ }^{\circ} \mathrm{C}\right)$ for $72 \mathrm{~h}$, and their growth curves were measured according to the method described previously (Li et al. 2017). Acid tolerance of $L$. plantarum D31 and T9 strains was examined according to the method described previously (Lee et al. 2014) with slight modification. The cell suspension of $L$. plantarum D31 and T9 strains was individually inoculated into acidic MRS broth (pH 2.0 to 7.0) and incubated at $37{ }^{\circ} \mathrm{C}$ for $24 \mathrm{~h}$. Tolerance of $L$. plantarum D31 and $\mathrm{T} 9$ strains to different concentrations of $\mathrm{NaCl}(0.0 \%$, $5.0 \%, 8.0 \%, 10.0 \%, 12.0 \%$, and $15.0 \%$ ) was determined according to the method described previously (Xin et al. 2014). Bile salt tolerance of L. plantarum D 31 and T9 strains was evaluated according to the method described previously (Shehata et al. 2016) with slight modification. The cell suspension of L. plantarum D31 and T9 strains was individually inoculated into the MRS broth containing different concentrations of bile salt $(0.0 \%, 0.05 \%$, $0.1 \%, 0.2 \%$, and $0.3 \%$ ) (Beijing Land Bridge Technology, Beijing, China) and incubated at $37{ }^{\circ} \mathrm{C}$ for $24 \mathrm{~h}$. Growth curves of these two strains at different acid, osmotic pressure, and bile salt conditions were individually determined as described above. Tolerance of $L$. plantarum D31 and T9 strains to artificial gastric and intestinal fluids was determined according to the method described previously (Zhang et al. 2016) with slight modification. The cell suspension of L. plantarum D31 and T9 strains was individually inoculated $(10 \%, v / v)$ into the artificial gastric and intestinal fluids and incubated at 37 ${ }^{\circ} \mathrm{C}$ for $180 \mathrm{~min}$ and $240 \mathrm{~min}$, respectively. The viable cell count assay was performed as described previously (Zhang et al. 2016). Artificial gastric fluid contained $0.35 \%$ pepsin and $0.2 \% \mathrm{NaCl}$ in $100 \mathrm{ml}$ of distilled water. The solution $\mathrm{pH}$ was adjusted to 2.0 with $1 \mathrm{~mol} / \mathrm{l} \mathrm{HCl}$ (Zhang et al. 2016). Artificial intestinal fluid contained $0.1 \%$ trypsin, $1.1 \% \mathrm{NaHCO}_{3}$, and $0.2 \% \mathrm{NaCl}$ in $100 \mathrm{ml}$ of 
distilled water. The solution $\mathrm{pH}$ was adjusted to 6.8 with $0.6 \mathrm{~mol} / \mathrm{l} \mathrm{NaOH}$ (Zhang et al. 2016). The artificial gastrointestinal fluids were sterilized by filtering through a $0.22-\mu \mathrm{m}$ membrane (Shanghai Sangon Biological Engineering Technology and Services Co., Ltd., Shanghai, China).

\section{Genomic DNA preparation}

Genomic DNA was prepared using a MiniBEST DNA extraction kit (Japan TaKaRa BIO, Dalian Company, China) following the manufacturer's instructions. Extracted DNA samples were analyzed by electrophoresis with a $0.7 \%$ agarose gel and visualized and recorded using a UVPEC3 Imaging system (UVP LLC, UpLand, CA, USA) (Figure $\mathrm{S} 1)$. The DNA concentration and purity $\left(A_{260} / A_{280}\right)$ were measured using a multi-mode microplate reader (BioTek Instruments, Inc., Winooski, VT). Only pure genomic DNA samples (a 260/280 nm absorbance ratio of 1.8-2.0) were used for genome sequencing.

\section{Genome sequencing and assembly}

The genome sequencing of $L$. plantarum D31 and $L$. plantarum T9 strains was carried out at Meiji Biological Medicine technology Ltd. (Shanghai, China) and Beijing Novogene Bioinformatics Technology Co., Ltd. (Beijing, China) using a Genome Sequencer Illumina HiSeq Xten platform (Illumina, CA, USA), respectively. Sequence quality was analyzed using the FastQC software (Brown et al. 2017). Raw sequencing reads were trimmed and assembled using the SOAPdenovo v2.04 software (http:// soap.genomics.org.cn/).

\section{Genome annotation}

Protein-encoding genes, tRNA genes, and rRNA genes were predicted using the GeneMarks (version 4.17) (Besemer et al. 2001) and Glimmer (version 3.02) (Delcher et al. 2007), tRNA_scan-SE (version 1.3.1) (Lowe and Eddy 1997), and RNAmmer (version 1.2) (Lagesen et al. 2007) software, respectively. Protein functions were predicted against the Clusters of Orthologous Groups (COG) database (Tatusov et al. 2001). Prophageassociated genes were predicted using a Prophage finder software (http://phast.wishartlab.com/). Clustered regularly interspaced short palindromic repeats (CRISPRs) were detected using the CRISPRFinder software (Grissa et al. 2007). Pfam domain, signal peptide and transmembrane domain, and transmembrane helices were predicted using the Web CD-Search Tool (Marchler-Bauer et al. 2015), SignalP 4.1 Serve (Petersen et al. 2011), and TMHMM (Krogh et al. 2001) software, respectively. Potential virulence factors were detected against the Virulence Factor Database (http://www.mgc.ac.cn/VFs/). Antibiotic resistance genes were searched in the Antibiotic Resistance Genes Database (Gupta et al. 2014).

\section{Comparative genome analysis}

Comparative genomic analysis was performed between L. plantarum D31 and T9 strains, and 50 L. plantarum strains whose complete genome sequences (Table S1) were available by 31 March 2018. The complete genome sequences were retrieved from the NCBI genome database (http://www.ncbi.nlm.nih.gov/genome). The Blastcluster software (http://www.ncbi.nlm.nih.gov/) was used for pan-genome analysis. Orthologous genes were analyzed using the CD-HIT software (Fu et al. 2012). Orthologous proteins were assigned only for proteins sharing both $60 \%$ amino acid identity and $80 \%$ sequence coverage, and strain-specific genes present in one genome had no significant BLAST hit against reference groups at $E \leq 1 \mathrm{e}^{-5}$. Homologous sequences of each gene were aligned using the MUSCLE software (Edgar 2004). A phylogenetic tree was constructed and viewed using the PHYML (Guindon and Gascuel 2003) and EvolView (Zhang et al. 2012) software, respectively. Bootstrap values above 50\% were obtained from 1000 bootstrap replications.

\section{Quantitative real-time reverse transcription PCR (qRT-PCR)}

Selected salt resistance-associated genes were validated by qRT-PCR assay as described previously (Sun et al. 2014; Zhu et al. 2017). L. plantarum D31 and T9 strains were incubated in the MRS medium supplemented with $8 \%$ and $5 \% \mathrm{NaCl}$, respectively, and cell culture grown to logarithmic growth phase was harvested by centrifugation as described above. Total RNA was prepared using the RNeasy Protect Bacterial Mini Kit (QIAGEN Biotech Co., Ltd., Hilden, Germany) according to the manufacturer's instructions. The DNA was removed from the samples using RNase-Free DNase Set (QIAGEN, Hilden, Germany). RNA samples were analyzed by $1 \%$ agarose gel electrophoresis at $100 \mathrm{~V}$ for $30 \mathrm{~min}$ (Figure S2), and its quality and quantity was assessed using a multi-mode microplate reader (BioTek Instruments, Inc., Winooski, VT). The reverse transcription reaction was performed using the PrimeScript ${ }^{\mathrm{TM}}$ RT reagent Kit with gDNA Eraser (Perfect Real Time) (Japan TaKaRa BIO, Dalian Company, Dalian, China) according to the manufacturer's protocol. RT-PCR was performed using the TB Green $^{\circ}$ Premix Ex Taqt $^{\mathrm{TM}}$ II (Tli RNaseH Plus) (Japan TaKaRa BIO, Dalian Company, Dalian, China) according to the manufacturer's instructions. A $20-\mu \mathrm{l}$ reaction volume contained $10 \mu \mathrm{l}$ TB Premix Ex TaqTM II, 0.4 $\mu$ l of each of the oligonucleotide primers $(10 \mu \mathrm{mol}), 0.4 \mu \mathrm{l}$ of ROX Reference DyeII, $2 \mu$ of cDNA template, and appropriate volume of sterile DNase/RNase-Free deionized water. All RT-PCR reactions were performed in a 7500 Fast Real-Time PCR System (Applied Biosystems, Foster City, CA, USA) under the following conditions: initial denaturation at $95{ }^{\circ} \mathrm{C}$ for $10 \mathrm{~min}$, followed by 40 cycles 
of denaturation at $95{ }^{\circ} \mathrm{C}$ for $15 \mathrm{~s}$, and primer annealing at $60{ }^{\circ} \mathrm{C}$ for $60 \mathrm{~s}$. The $16 \mathrm{~S}$ rRNA gene was used as the reference gene, as previously described (Zhu et al. 2017). The expression of the $16 \mathrm{~S}$ rRNA gene in L. plantarum D31 and T9 strains grown to the logarithmic growth phase in MRS medium supplemented with no $\mathrm{NaCl}$ was used as a reference/baseline, respectively. The data were analyzed using the Applied Biosystems 7500 software, and the relative expression ratio was calculated for each target gene by using the delta-delta threshold cycle $(\mathrm{Ct})$ method (Livak and Schmittgen 2001). Oligonucleotide primers were designed using the Primer 5.0 software (http://www.premierbiosoft.com/) and synthesized by Shanghai Sangon Biological Engineering Technology Services Co. Ltd. (Shanghai, China) (Table 1). All determinants were performed in triplicate.

\section{Genome sequence accession numbers}

The draft genomes of L. plantarum D31 and L. plantarum T9 strains were deposited in GenBank under the accession numbers RCFP00000000 and RBAI00000000, respectively.

\section{Results and discussion}

To date, more than 50 complete genome sequences of $L$. plantarum strains are available in public databases; nevertheless, little genome information is for the salttolerant LAB. Moreover, only few $L$. plantarum strains have been reported to tolerate osmotic stress, e.g., $L$. plantarum ST-III and L. plantarum ATCC 14917 strains (El-Gendy et al. 1983; Rao et al. 2004; Chen et al. 2012; Vasyliuk et al. 2014; Xin et al. 2014). In this study, for the first time, we evaluated tolerance of $L$. plantarum D31 and L. plantarum T9 strains, isolated from Chinese traditional fermented food, to different stress conditions (temperatures, acid, osmolality, and artificial gastrointestinal fluids).

\section{Survival of L. plantarum D31 and T9 strains at different temperatures}

Growth curves of L. plantarum D31 and T9 strains incubated at different temperatures $\left(15\right.$ to $\left.45{ }^{\circ} \mathrm{C}\right)$ were determined, and the resulting data are illustrated in Fig. 1a-c. No distinct difference in growth was observed between these two strains at an optional growth temperature of 37 ${ }^{\circ} \mathrm{C}$ (Fig. 1c). Moreover, at the lower $\left(15^{\circ} \mathrm{C}\right)$ or higher $(45$ ${ }^{\circ} \mathrm{C}$ ) temperatures, the growth of these two strains was obviously inhibited, and their $\mathrm{OD}_{600 \mathrm{~nm}}$ values showed no significant change for $72 \mathrm{~h}$ (figure not shown). Nevertheless, when incubated at $20^{\circ} \mathrm{C}, \mathrm{L}$. plantarum T9 still grew well but with a long lag phase $(18 \mathrm{~h})$ and reached stationary growth phase (SGP) at $54 \mathrm{~h}$, whereas the growth of $L$. plantarum D31 was retarded with a longer lag phase (54 h) and entered into the SGP at 72 h (Fig. 1a). Similar growth phenotypes of these two strains were observed at $25{ }^{\circ} \mathrm{C}$ as did at $20{ }^{\circ} \mathrm{C}$ (Fig. 1b), suggesting the mediumtemperature growth feature of L. plantarum T9 and D31 strains.

\section{Survival of L. plantarum D31 and T9 strains at acidic pH conditions}

Tolerance of $L$. plantarum under acid stress has been reported (Huang et al. 2016). In this study, as shown in Fig. 2, L. plantarum T9 and D31 strains were able to grow at pH 5.0 and optimally at pH 6.0 to 7.0, consistent with previous research (Nyanga-Koumou et al. 2012). Additionally, L. plantarum D31 did not grow at pH 4.0, whereas $L$. plantarum T9 was observed to grow slowly at this $\mathrm{pH}$ condition. Moreover, no cell growth of these two strains was observed under more acidic conditions with $\mathrm{pH}$ values lower than 3.0 (Fig. 2).

Tolerance of L. plantarum D31 and T9 strains to different concentrations of $\mathrm{NaCl}$

Tolerance of L. plantarum D31 and T9 strains to different concentrations of $\mathrm{NaCl}$ was determined, and the resulting data are illustrated in Fig. 3. The two strains were found to grow well in the MRS medium supplemented with $0.0-5.0 \% \mathrm{NaCl}$ at $37{ }^{\circ} \mathrm{C}$. Also, L. plantarum D31 was able to grow at $8.0 \% \mathrm{NaCl}$, whereas the growth of $L$. plantarum $\mathrm{T} 9$ was obviously inhibited at this $\mathrm{NaCl}$ concentration. No cell growth of these two strains was found when the $\mathrm{NaCl}$ concentration was more than $8.0 \%$ (Fig. 3).

\section{Survival of $L$. plantarum D31 and T9 strains in different concentrations of bile salt}

Previous research has reported bile-tolerant $L$. plantarum and key proteins by comparative proteomic analysis (Hamon et al. 2011). In this study, as shown in Fig. 4, bile salt tolerance of L. plantarum D31 and T9 strains was examined. The growth of these two strains was obviously inhibited at $0.05 \%$ bile salt. Moreover, neither L. plantarum D31 nor T9 strains could withstand more than $0.1 \%$ bile salt (Fig. 4).

\section{Survival of L. plantarum D31 and T9 strains in artificial human gastric and intestinal fluids}

Tolerance of L. plantarum D31 and T9 strains to artificial gastric and intestinal fluids was also determined. After treated in the artificial gastric fluid for $180 \mathrm{~min}$, the growth of $L$. plantarum D31 was completely inhibited, while an extremely low survival rate $(0.03 \%)$ was observed for $L$. plantarum T9. Likewise, the growth of $L$. plantarum D31 and T9 strains was also significantly reduced in artificial intestinal fluid for $240 \mathrm{~min}$, and the survival rates were $11.7 \%$ and $0.87 \%$ for L. plantarum D31 and T9 strains, respectively (figures not shown). 
Table 1 The oligonucleotide primers used in the qRT-PCR assay in this study

\begin{tabular}{|c|c|c|c|c|}
\hline Locus/gene & Description of encoded protein & Sequence $\left(5^{\prime}->3^{\prime}\right)$ & Predicted product length (bp) & Source \\
\hline \multicolumn{5}{|l|}{ L. plantarum D31 } \\
\hline \multirow[t]{2}{*}{ D7Y65_00120 } & Potassium transporter Kup & F: ATCGTTGGCTCTTTAATCCC & 166 & This study \\
\hline & & R: AACAAGCACGAAGGCGGTAT & & \\
\hline \multirow[t]{2}{*}{ D7Y65_03505 } & Cell membrane protein & F: TGTGACTGGGTITGCTGAAT & 124 & This study \\
\hline & & R: CTCCAACACCGCATCTTCTA & & \\
\hline \multirow[t]{2}{*}{ D7Y65_06915 } & Co-chaperone GroES & F: ATGACGGTCGTGTTITAGAT & 117 & This study \\
\hline & & R: CCTTGATACTTGACTTCGGT & & \\
\hline \multirow[t]{2}{*}{ D7Y65_06920 } & Chaperonin GroEL & F: GCTTCTGTTTCAGCCCTTCT & 106 & This study \\
\hline & & R: TACATCATACCGCCCATACC & & \\
\hline \multirow[t]{2}{*}{ D7Y65_06955 } & Sigma-54 modulation protein & F: CAAGCAATTCGGGACTACGT & 113 & This study \\
\hline & & R: TTTAGCCGTCTTGTCTGGGT & & \\
\hline \multirow[t]{2}{*}{ D7Y65_09830 } & Molecular chaperone DnaJ & F: TGGCGTATTAGTCTGTACCTG & 164 & This study \\
\hline & & R: TGAAGTTGAAGATGCGATC & & \\
\hline \multirow[t]{2}{*}{ D7Y65_09835 } & Molecular chaperone DnaK & F: ACCAAGTGAAAGTGGCGTAA & 139 & This study \\
\hline & & R: AAAGTGGACTGGCAAAGAAT & & \\
\hline \multirow[t]{2}{*}{ D7Y65_13150 } & Potassium transporter Kup & F: GGACACGAAAGCCCAGGTAT & 145 & This study \\
\hline & & R: TTAGACAAGTGGCCGAAACG & & \\
\hline \multirow[t]{2}{*}{ D7Y65_13295 } & LysR family & F: TGAAGGCCGTATTATGGATG & 149 & This study \\
\hline & & R: GATTGCCGAAGAATTTGACC & & \\
\hline \multirow[t]{2}{*}{ D7Y65_02550* } & Metal-independent a-mannosidase & F: AGATACGGGAATGATTTGGT & 182 & This study \\
\hline & & R: TACGCACAGTCGTCTGGAGT & & \\
\hline \multirow[t]{2}{*}{ D7Y65_07055* } & Glycosyl hydrolase family 8 & F: CGGTGAGTGTTGGTGGTGAA & 137 & This study \\
\hline & & R: CGGCGAACTGTCTTGCTGTA & & \\
\hline \multirow[t]{2}{*}{ D7Y65_13825* } & Carboxypeptidase & F: ATAATAGTGCGGATTGTGCT & 181 & This study \\
\hline & & R: TACTACCGTGACGATGGGAC & & \\
\hline \multirow[t]{2}{*}{ D7Y65_15155* } & Potassium transporter Kup & F: AGCAGATGGCACCCTAACAC & 169 & This study \\
\hline & & R: AACGACGGCAGTACCAAACC & & \\
\hline \multirow[t]{2}{*}{ D7Y65_15160* } & Kdp E & F: CTGCACTTTGTCAGCGTCCTC & 104 & This study \\
\hline & & R: CCGATATGGATGGGATGGAC & & \\
\hline \multirow[t]{2}{*}{ D7Y65_15165* } & KdpD & F: TTTGGTTACGCTGCTTCTT & 106 & This study \\
\hline & & R: TAACATTAGCCTTGCCCATC & & \\
\hline \multirow[t]{2}{*}{ D7Y65_15180* } & $\mathrm{Kdp} A$ & F: AACCACCAGTTGTTTGAGGA & 142 & This study \\
\hline & & R: GGTATCCAACGTACAGAGGC & & \\
\hline \multicolumn{5}{|l|}{ L. plantarum T9 } \\
\hline \multirow[t]{2}{*}{ D7Y66_02210 } & Cell membrane protein & F: TACCGGCTGCTTATGATACTTC & 173 & This study \\
\hline & & R: CTCCAACACCGCATCTTCTA & & \\
\hline \multirow[t]{2}{*}{ D7Y66_03635 } & Co-chaperone GroES & F: CAATGACGGTCGTGTTTTAG & 108 & This study \\
\hline & & R: CCTTGATACTTGACTTCGGT & & \\
\hline \multirow[t]{2}{*}{ D7Y66_03640 } & Chaperonin GroEL & F: GCTTCTGTTTCAGCCCTTCT & 113 & This study \\
\hline & & R: TACATCATACCGCCCATACC & & \\
\hline \multirow[t]{2}{*}{ D7Y66_03675 } & Sigma-54 modulation protein & F: CAAGCAATTCGGGACTACGT & 115 & This study \\
\hline & & R: TAGCCGTCTTGTCTGGGTGA & & \\
\hline D7Y66_07525 & Potassium transporter Kup & F: CTCAGCTATTTCGGTCAGGC & 103 & This study \\
\hline
\end{tabular}


Table 1 The oligonucleotide primers used in the qRT-PCR assay in this study (Continued)

\begin{tabular}{|c|c|c|c|c|}
\hline Locus/gene & Description of encoded protein & Sequence $\left(5^{\prime}->3^{\prime}\right)$ & Predicted product length (bp) & Source \\
\hline \multirow[t]{2}{*}{ D7Y66_08075 } & \multirow[t]{2}{*}{ Molecular chaperone DnaJ } & F: CCAGCAGGAACCGTCACTTT & \multirow[t]{2}{*}{140} & \multirow[t]{2}{*}{ This study } \\
\hline & & R: CCACTCGGTCGAATGATGAG & & \\
\hline \multirow[t]{2}{*}{ D7Y66_08080 } & \multirow[t]{2}{*}{ Molecular chaperone DnaK } & F: ACCAAGTGAAAGTGGCGTAA & \multirow[t]{2}{*}{139} & \multirow[t]{2}{*}{ This study } \\
\hline & & R: AAAGTGGACTGGCAAAGAAT & & \\
\hline \multirow[t]{2}{*}{ D7Y66_11330 } & \multirow[t]{2}{*}{ LysR family } & F: GGTITCGAGACCGGCTAATA & \multirow[t]{2}{*}{179} & \multirow[t]{2}{*}{ This study } \\
\hline & & R: GCAACTTGCTGAACACGCTA & & \\
\hline \multirow[t]{2}{*}{ D7Y66_13435 } & \multirow[t]{2}{*}{ Potassium transporter Kup } & F: GGCAGTACCAAACCCTTGAA & \multirow[t]{2}{*}{168} & \multirow[t]{2}{*}{ This study } \\
\hline & & R: TTGTTAGCAGATGGCACCCT & & \\
\hline \multirow[t]{2}{*}{ Ip_3505 } & \multirow[t]{2}{*}{ Acetyl esterase } & F: TTCGTGTTGGTAACTCGTGGGT & \multirow[t]{2}{*}{117} & \multirow[t]{2}{*}{ This study } \\
\hline & & R: TGTTGCATGGCTTAGGTGGG & & \\
\hline \multirow[t]{2}{*}{ 16S RNA } & & F: AAGGGTTTCGGCTCGTAAAA & \multirow[t]{2}{*}{247} & \multirow[t]{2}{*}{ Sun et al. 2014} \\
\hline & & R: TGCACTCAAGTTTCCCAGTT & & \\
\hline
\end{tabular}

$F$ forward primer, $R$ reverse primer; ${ }^{*}$ The genes detected in L. plantarum D31 strain

Genome features of $L$. plantarum D31 and T9 strains Draft genomes of L. plantarum D31 and T9 strains were determined using the Illumina sequencing technique in order to get insights into possible molecular mechanisms of their salt stress tolerance. This analysis generated $8,987,722$ and 6,246,667 reads for $L$. plantarum D31 and T9 with sequencing depth of 406-fold and 277-fold, respectively. The L. plantarum D31 draft genome contains 3,315,786 bp with a GC content of $44.5 \%$. The final assembly comprised 72 scaffolds. Total 3251 genes were predicted, including 3106 predicted protein-coding genes and 48 RNA genes (Table 2). Among these genes, approximately $75.4 \%$ had a predicted function, and $58.3 \%$ were assigned to COG (Table S2). One 39.9-kb intact prophage element (scaffold 6: 70,583-110,507 bp) and one CRISPR repeat array (23 bp, scaffold 50: 77-343 bp) were identified in L. plantarum D31 genome.

The L. plantarum T9 draft genome contained 3,388, $070 \mathrm{bp}$ with a GC content of $44.1 \%$. The final assembly yielded 158 scaffolds. Total 3515 genes were predicted, including 3223 predicted protein-coding genes and 77 RNA genes (Table 2). Among the predicted genes, about $73.7 \%$ had a predicted function, and $55.1 \%$ were assigned to COG (Table S2). Two intact prophage elements (76.5 kb, scaffold 1: 73,403-149,937 bp; $40.8 \mathrm{~kb}$, scaffold 6: 16, 933-57,799 bp) and one CRISPR repeat array (37 bp, scaffold 52: 11,856-12,956 bp) were identified in L. plantarum $\mathrm{T} 9$ genome, respectively.

Additionally, no virulence gene was identified in L. plantarum D31 and T9 draft genomes. A potential antibiotic gene baca encoding a bacitracin resistance protein (D7Y65_ 11270, D7Y66_07705) was identified in the two genomes.

The features of these two draft genomes are summarized in Table 2. The draft genomes of L. plantarum D31 and T9 were submitted to GenBank under the accession numbers RCFP00000000 and RBAI00000000, respectively.

\section{Phylogenetic relatedness of $L$. plantarum strains}

As shown in Fig. 5, a phylogenetic tree was construed, based on 151,630 homologous amino acid sequences


Fig. 1 Growth curves of L. plantarum D31 and T9 strains incubated in the MRS medium (pH 6.8) at different temperatures. a $20^{\circ} \mathrm{C}, \mathbf{b} 25^{\circ} \mathrm{C}$, and $\mathbf{c}$ $37^{\circ} \mathrm{C}$ 

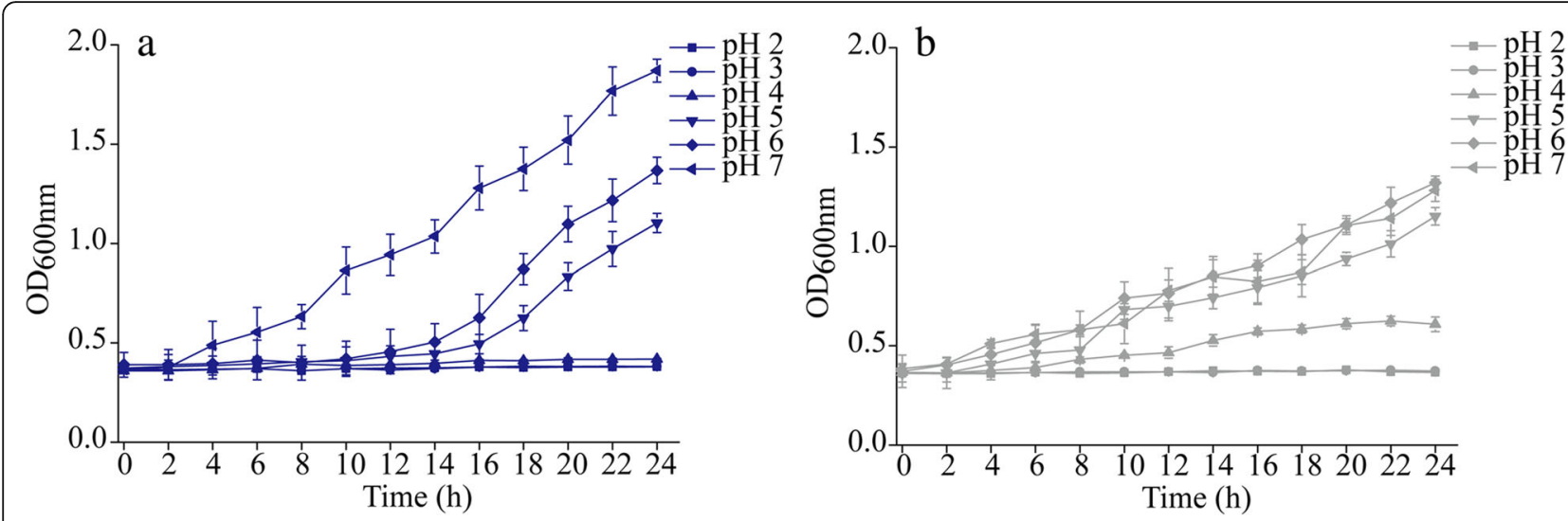

Fig. 2 Effects of different initial pH on the growth of L. plantarum D31 (a) and T9 (b) strains

identified from the $52 \mathrm{~L}$. plantarum genomes analyzed in this study, among which complete genome sequences of $50 \mathrm{~L}$. plantarum strains were available and retrieved from the GenBank database. This analysis revealed three distinct clusters, designated cluster $\alpha, \beta$, and $\gamma$. L. plantarum D31 and T9 genomes were classified as two singletons (cluster $\alpha$ and cluster $\beta$ ). They were phylogenetically distant from the other $L$. plantarum genomes that were grouped into cluster $\gamma$. The cluster $\gamma$ was further classified into two subclusters I and II, including 13 and 36 genomes, respectively, which were recovered from diverse sources, such as the human saliva and gut, fermented fish, pickle, stinky tofu, and cow milk. Additionally, L. plantarum D31 and T9 genomes were distant from the salt-tolerant $L$. plantarum ST-III (ASM14881V1).

Strain-specific genes in L. plantarum D31 and T9 genomes Based on the $52 \mathrm{~L}$. plantarum genome sequences analyzed in this study, comparative genomic analysis revealed 173 strain-specific genes in L. plantarum D31 genome, of which 167 genes encoded hypothetical proteins, suggesting possible strain-specific mechanisms of stress tolerance and/or niche adaptation. The remaining strainspecific genes were involved in cell wall biosynthesis, carbohydrate metabolism, and stress response, e.g., the Lfructose isomerase (D7Y65_15415), pilus assembly protein (D7Y65_15865), bleomycin binding protein Ble-MBL (D7Y65_15890), molecular chaperone DnaJ (D7Y65_ 15980), single-stranded DNA-binding protein (D7Y65 16040), and conjugal transfer protein TraG (D7Y65 16080). Likewise, L. plantarum T9 had 112 strain-specific genes; however, most of which (111 genes) encoded hypothetical proteins, and one encoded a helix-turn-helix domain-containing protein (D7Y66_00865).

\section{Genomic insights into possible mechanisms of the salt tolerance of $L$. plantarum D31 and T9 strains Recovery of intracellular ion balance}

The sodium/proton $\left(\mathrm{Na}^{+} / \mathrm{H}^{+}\right)$reverse transporter on cytoplasma membrane is the main way of microbial efflux of $\mathrm{Na}^{+}$, which regulates intracellular $\mathrm{pH}$ homeostasis (Padan et al. 2005). It has been reported that $L$. plantarum 5-2 genome contained eight genes encoding
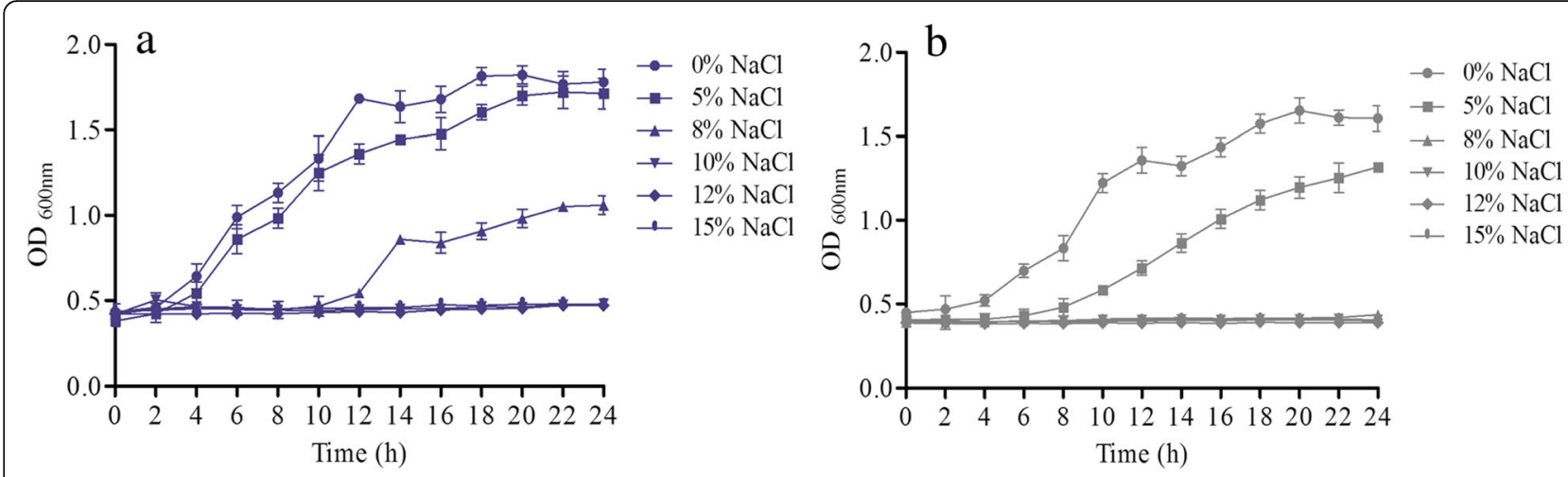

Fig. 3 Tolerance of L. plantarum D31 (a) and T9 (b) strains to different concentrations of $\mathrm{NaCl}$ 

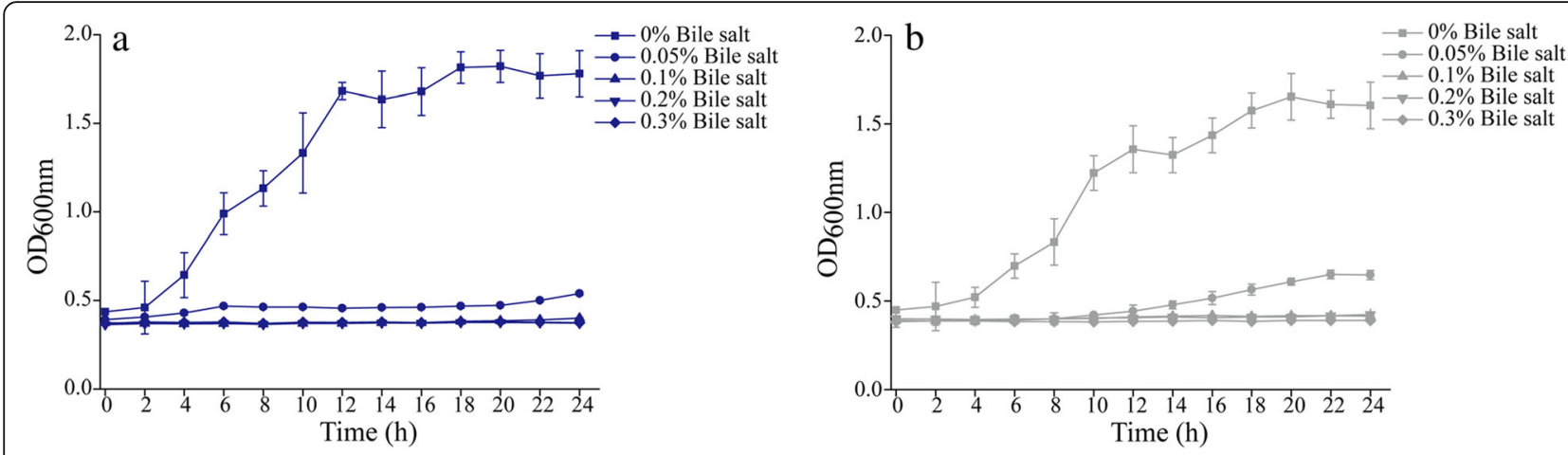

Fig. 4 Survival of L. plantarum D31 (a) and T9 (b) strains in different concentrations of bile salt

the $\mathrm{Na}^{+} / \mathrm{H}^{+}$antiporters (Liu et al. 2015). In this study, comparative genomic analysis revealed at least ten, nine, and six genes encoding $\mathrm{Na}^{+} / \mathrm{H}^{+}$antiporters in L. plantarum D31, T9, and ST-III genomes, respectively. Potassium $\left(\mathrm{K}^{+}\right)$is the most abundant ion in bacterial cytoplasm and plays a pivotal role in ion homeostasis (Epstein 2003). Previous research has indicated that the $k d p$ system in $L$. plantarum ST-III enabled the bacterium growing in the presence of curing salts $(7.5 \% \mathrm{NaCl})$ (Chen et al. 2012). In the $k d p$ system, the sensor kinase $\mathrm{KdpD}$ and the response regulator $\mathrm{KdpE}$ controlled the induction of the $k d p A B C$ operon in response to an osmotic upshift (Peddie et al. 1994; Grissa et al. 2007; Petersen et al. 2011). In this study, a typical $k d p A B C D E$ gene locus was also identified in L. plantarum D31 genome (D7Y65_15160 to D7Y65_15180), which had high sequence similarity (95\%) with $k d p$ genes (YP 003927890.1 to YP_003927894.1) in L. plantarum ST-III genome. The $k d p$ cluster was also identified in another L. plantarum GB-LP3 genome, but absent from L. plantarum T9 draft genome. It has also been reported that $\mathrm{K}^{+}$is accumulated far above the normal level in the primary response in Escherichia coli to the osmotic upshift (Heermann et al. 2009). In E. coli, kup is the major $\mathrm{K}^{+}$ uptake system under hyperosmotic stress and low $\mathrm{pH}$ conditions (Zakharyan and Trchounian 2001). In this study, upstream of the $k d p$ gene cluster, a $\mathrm{K}^{+}$-transport system gene kup was identified in L. plantarum D31 genome (D7Y65_15155), showing 94\% sequence similarity with kup genes (WP_013356293.1) in L. plantarum ST-III, which may act as the major $\mathrm{K}^{+}$uptake system in the MRS medium with $7.5 \% \mathrm{NaCl}$ (Chen et al. 2012). Moreover, another two kup genes (D7Y65_13150, D7Y65_00120) were also identified from L. plantarum D31 genome, while only two were identified from $L$. plantarum T9 (D7Y66_07525, D7Y66_13435).

Table 2 L. plantarum D31 and T9 genome statistics

\begin{tabular}{llllll}
\hline Feature & L. plantarum D31 & & & L. plantarum T9 \\
\cline { 2 - 5 } & Value & $3,315,786$ & 100.00 & Value & Percentage of total \\
\hline Genome size (bp) & $2,777,217$ & 83.76 & $3,388,070$ & 100.00 \\
DNA coding (bp) & $1,474,530$ & 44.47 & $2,788,032$ & 82.29 \\
DNA G + C (bp) & 72 & & $1,494,478$ & 44.11 \\
DNA scaffold & 3251 & 100.00 & 158 & 100.00 \\
Total gene & 3106 & 95.54 & 3515 & 91.69 \\
Protein-coding gene & 48 & 1.48 & 3223 & 2.19 \\
RNA gene & 97 & 2.98 & 77 & 6.12 \\
Pseudo gene & 2450 & 75.36 & 215 & 73.68 \\
Genes with function prediction & 1896 & 58.32 & 2590 & 1935 \\
Genes assigned to COG & 2530 & 77.82 & 2578 & 55.05 \\
Genes with Pfam domain & 138 & 4.24 & 143 & 73.34 \\
Genes with signal peptide & 845 & 25.99 & 876 & 4.07 \\
Genes with transmembrane helices & 1 & & 1 & 24.92 \\
CRISPR repeat & 1 & & 2 & \\
Intact prophage & & & & \\
\hline
\end{tabular}




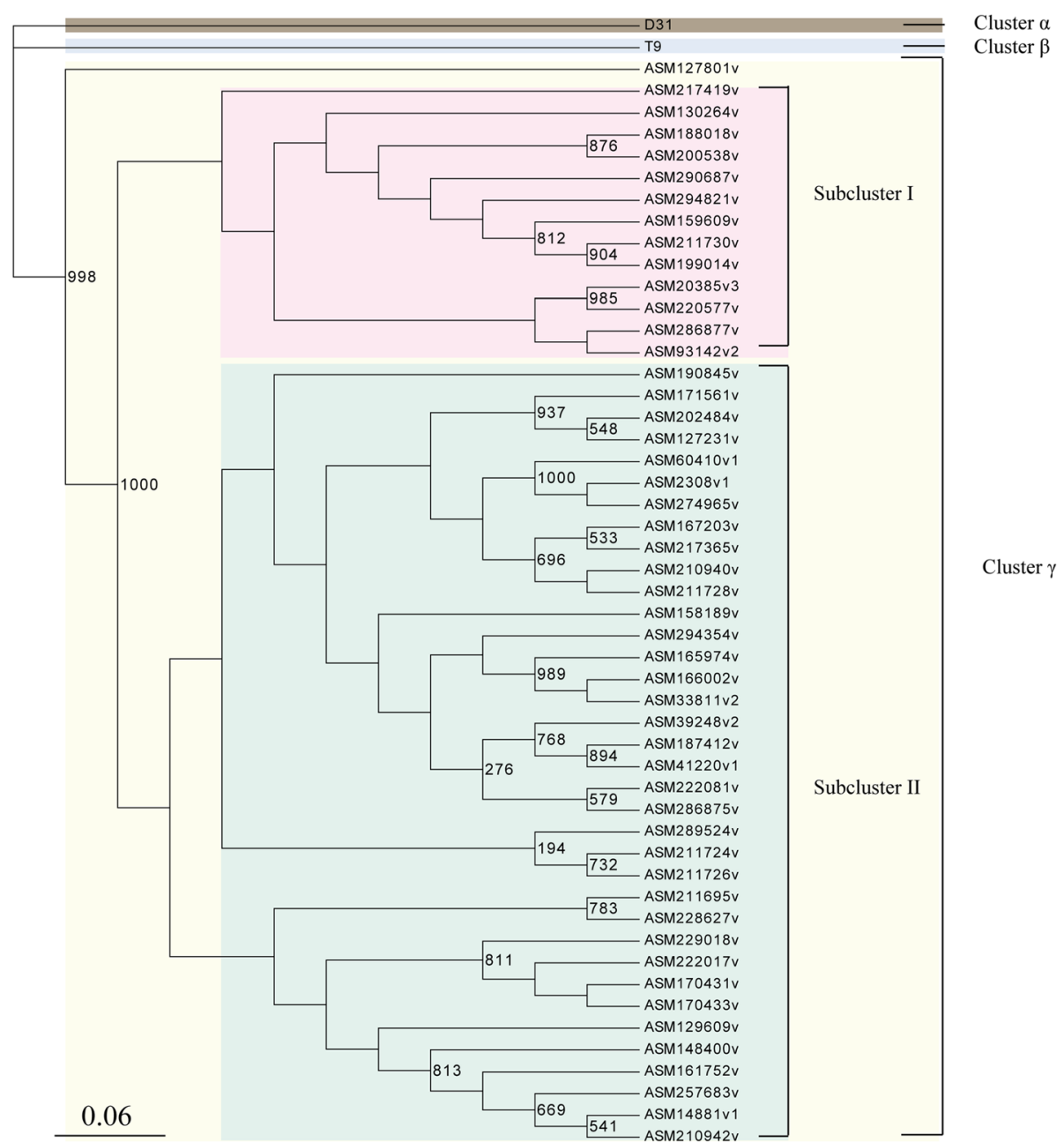

Fig. 5 Phylogenetic analysis of the 52 L. plantarum genomes analyzed in this study. The draft genome sequences of L. plantarum D31 and T9 were obtained in this study, while the complete genome sequences of the other $50 \mathrm{~L}$. plantarum strains were available in the NCBI genome database

\section{Absorption or synthesis of compatible solutes}

Accumulation of certain compatible solutes (e.g., glycine and betaine) is a common metabolic adaptation found in diverse species (Oshone et al. 2017). The osmotic function of a compatible solute depends on the degree of methylation and length of the hydrocarbon chain (Peddie et al. 1994). It has been reported that the electrolytemediated osmolality up-shifts led to the accumulation of compatible solutes (Glaasker et al. 1998). In this study, genes involved in absorption or synthesis of compatible solutes were identified in L. plantarum D31 and T9 genomes. For instance, the genes encoding glycine/betaine/carnitine $\mathrm{ABC}$ transporters (opuABCD, choSQ) were identified in L. plantarum D31 (D7Y65_03265 to D7Y65_03280) and T9 (D7Y66_01970 to D7Y66_01985) genomes, respectively, which had high sequence similarity (99\%) with the corresponding genes in L. plantarum ST-III (Kleerebezem et al. 2003). Moreover, the gene involved in nitrate/sulfonate/bicarbonate $A B C$ transporter was identified in L. plantarum D31 (D7Y65 10050) and T9 genomes (D7Y66_08295), respectively, which was upregulated in response to salt stress in $L$. plantarum ST-III (Kleerebezem et al. 2003). These genes were involved in multi-component binding-proteindependent transport systems for glycine, betaine, and camitine, and accumulated to high levels in the cell in response to increased external osmolality (Huang et al. 2010). Additionally, proline is essential for primary metabolism in salt stress and plays a molecular chaperone role in maintaining the $\mathrm{pH}$ of the cytosolic redox status of the cell (Kido et al. 2013). Previous research has indicated that pro $A B C$ genes are related to the accumulation of proline and enable bacteria to withstand high osmotic pressure (Mahan and Csonka 1983). In this study, a proABC gene cluster was identified in L. plantarum D31 (D7Y65_02230, D7Y65_02235, D7Y65_14760) and T9 
(D7Y66_05380, D7Y66_05385, D7Y66_11000) genomes, respectively, which may be involved in their tolerance to the salt stress.

\section{Modulation of cell membrane}

The composition of the cell envelope plays an important role in bacterial osmo-adaptation (Sun et al. 2014). Salt stress triggers alterations in structure and composition of the cell peptidoglycan layer (Piuri et al. 2010). In this study, comparative genomic analysis also revealed the genes involved in the modulation of cell membrane in $L$. plantarum D31 and T9 genomes. For instance, the genes encoding a lysyl-phosphatidylglycero (D7Y65_14200, D7Y66_03470) and a phosphatidylglycero (D7Y65 14200/D7Y65_07030, D7Y66_03470/D7Y66_15490) were identified in L. plantarum D31 and T9 genomes, respectively. Moreover, the gene encoding a membrane protein (D7Y65_03505, D7Y66_02210) was also identified in L. plantarum D31 and T9 genomes, which had 50\% sequence similarity with the gene (CCI6_RS12035) in Frankia sp. Ccl6, which was involved in cell wall/ membrane/envelop biosynthesis and upregulated under the salt stress (Oshone et al. 2017). L. plantarum D31 and T9 also contain the genes encoding a 1-acylglycerol3-phosphate O-acyltransferase (D7Y65_09990, D7Y66_ 08235) and a phosphatidylglycerophosphatase A (D7Y65_11075, D7Y66_07900), which are involved in cell wall modification to response to the salt stress in Frankia strains (Oshone et al. 2017).

\section{Stress response}

Previous studies have indicated that induction of onecomponent regulatory systems (e.g., GroES-GroEL and DnaK-DnaJ) is related with acid, ethanol, cold, osmotic, starvation, and temperature stresses (Sugimoto et al. 2008). DnaK was first found in heat stress in E. coli (Arsene et al. 2000), but it can also be overexpressed under salt stress (Bucka-Kolendo and Sokolowska 2017). In this study, the genes encoding one-component regulatory systems DnaK-DnaJ and GroES-GroEL were identified in L. plantarum D31 (D7Y65_09835 to D7Y65 09830, D7Y65_06915 to D31_D7Y65_06920) and T9 genomes (D7Y66_08080 to D7Y66_08075, D7Y66_03635 to D7Y66_15720), respectively. A gene encoding GroESlike protein (D7Y65_06915) was also identified in $L$. plantarum D31 and ATCC14917 genomes. Qin et al. reported that a marine bacterium Zunongwangia profunda (MCCC 1A01486) showing extreme salt tolerance has a cold-active and salt-tolerant $\alpha$-amylase (AmyZ) belonging to glycoside hydrolase family 13 (Qin et al. 2014). Kang et al. also reported that the gene lj0569 encoding a conserved domain of glycoside hydrolase family 31 was present in Lactobacillus johnsonii NCC533, which was found to survive in a high concentration of $\mathrm{NaCl}(29 \mathrm{~g} / \mathrm{l})$ (Kang et al. 2009). The genes encoding proteins that

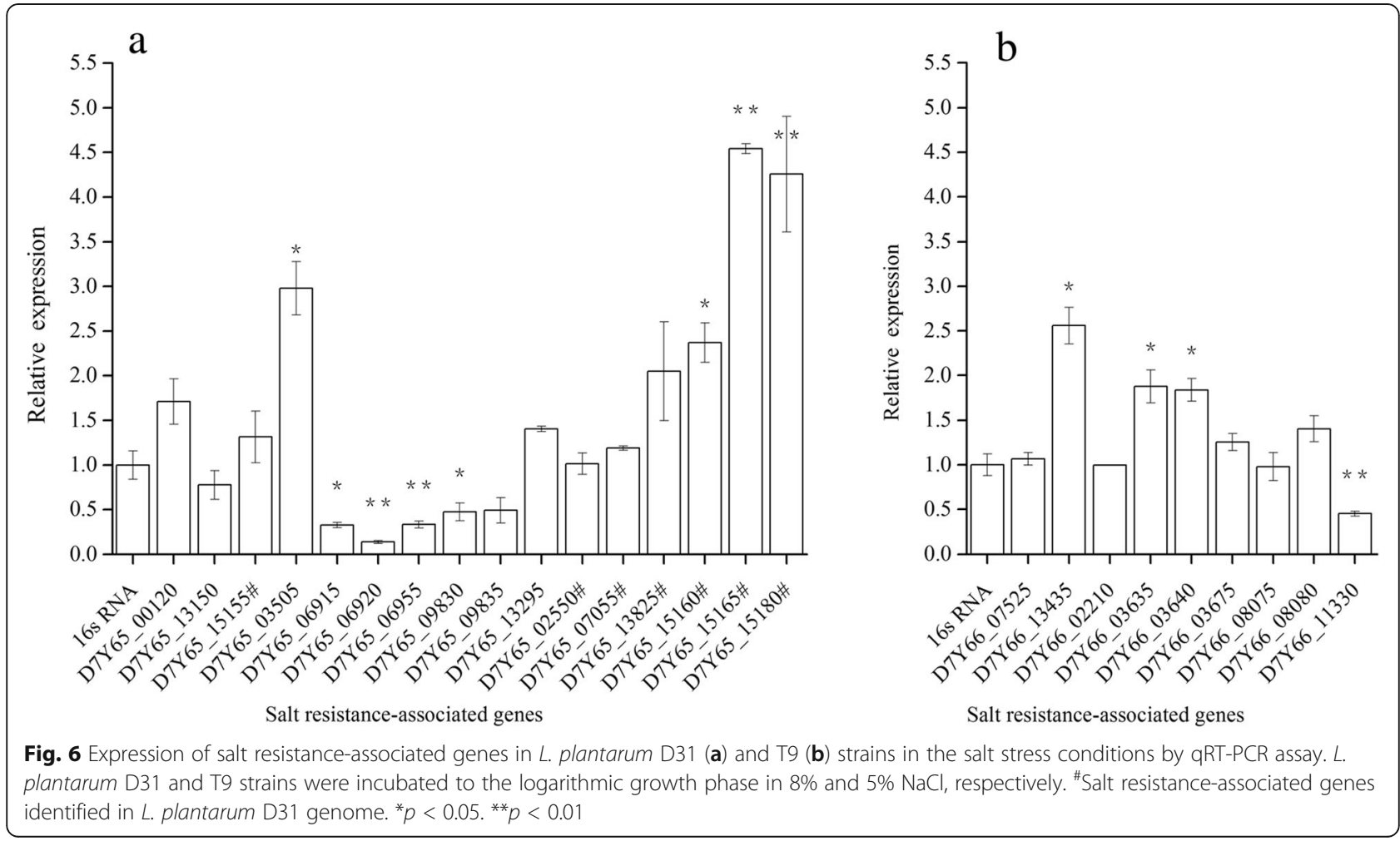


have conserved domains of glycoside hydrolase families 125 and 8 were identified in L. plantarum D31 genome (D7Y65_02550, D7Y65_07055), which had 99\% sequence similarity with corresponding genes (WP_013356072.1, WP_033099061.1) in salt-tolerant $L$. plantarum ST-III.

\section{Regulators}

Previous studies have revealed important roles of regulators in stress tolerance of $L$. plantarum (Wang et al. 2016; Jia et al. 2018). L. plantarum D31 draft genome contained approximately 229 genes encoding transcriptional or response regulators, which represented approximately $7.4 \%$ of its protein-encoding genes, while L. plantarum T9 contained approximately 208 such genes, which represented approximately $6.5 \%$ of its protein-encoding genes. These genes may modulate global regulatory networks that are essential for bacterial adaptation to changing environment. For instance, several genes encoding transcriptional factors of GntR, TetR, Crp/Fnr, and LysR families were identified in L. plantarum D31 and T9 genomes (Table S3), which have been implicated in bacteria stress responses including heat and osmotic shock (Ramos et al. 2005). The gene (D7Y65_13295, D7Y66_11330) encoding transcriptional regulator of the LysR family was identified in L. plantarum D31 and T9 genomes, which shared 61.1\% similarity at amino acid sequence level with the gene (CCI6_RS20460) in a salt stress-tolerant Frankia sp. Ccl6 strain. Genes encoding a RNA polymerase sigma factor RpoD (D7Y65_04790, D7Y66_09275), an Sadenosylmethionine synthetase (D7Y65_12145, D7Y66_ 14505), a DNA-directed RNA polymerase subunit beta (D7Y65_08230, D7Y66_06445), and an amino acid permease (D7Y65_06925, D7Y66_03645) were also identified in L. plantarum D31 and T9 genomes, respectively. The expression of these genes was upregulated in Frankia sp. Ccl6 grown in $1000 \mathrm{mmol} / \mathrm{l} \mathrm{NaCl}$ (Oshone et al. 2017). In addition, many differentially expressed proteins responding to $6.0 \% \mathrm{NaCl}$ stress were identified in L. plantarum ATCC14917 (Wang et al. 2016), among which the genes encoding a triosephosphate isomerase (D7Y65_07215, D7Y66_03905), a glyceraldehyde-3-phosphate dehydrogenase (D7Y65_07205, D7Y66_03895), a fructosebisphosphate aldolase (D7Y65_00895, D7Y66_11760), a trigger factor (D7Y65_10490, D7Y66_10765), a carbamoyl phosphate synthase large subunit (D7Y65_06465, D7Y66_ 02930), an orotate phosphoribosyltransferase (D7Y65

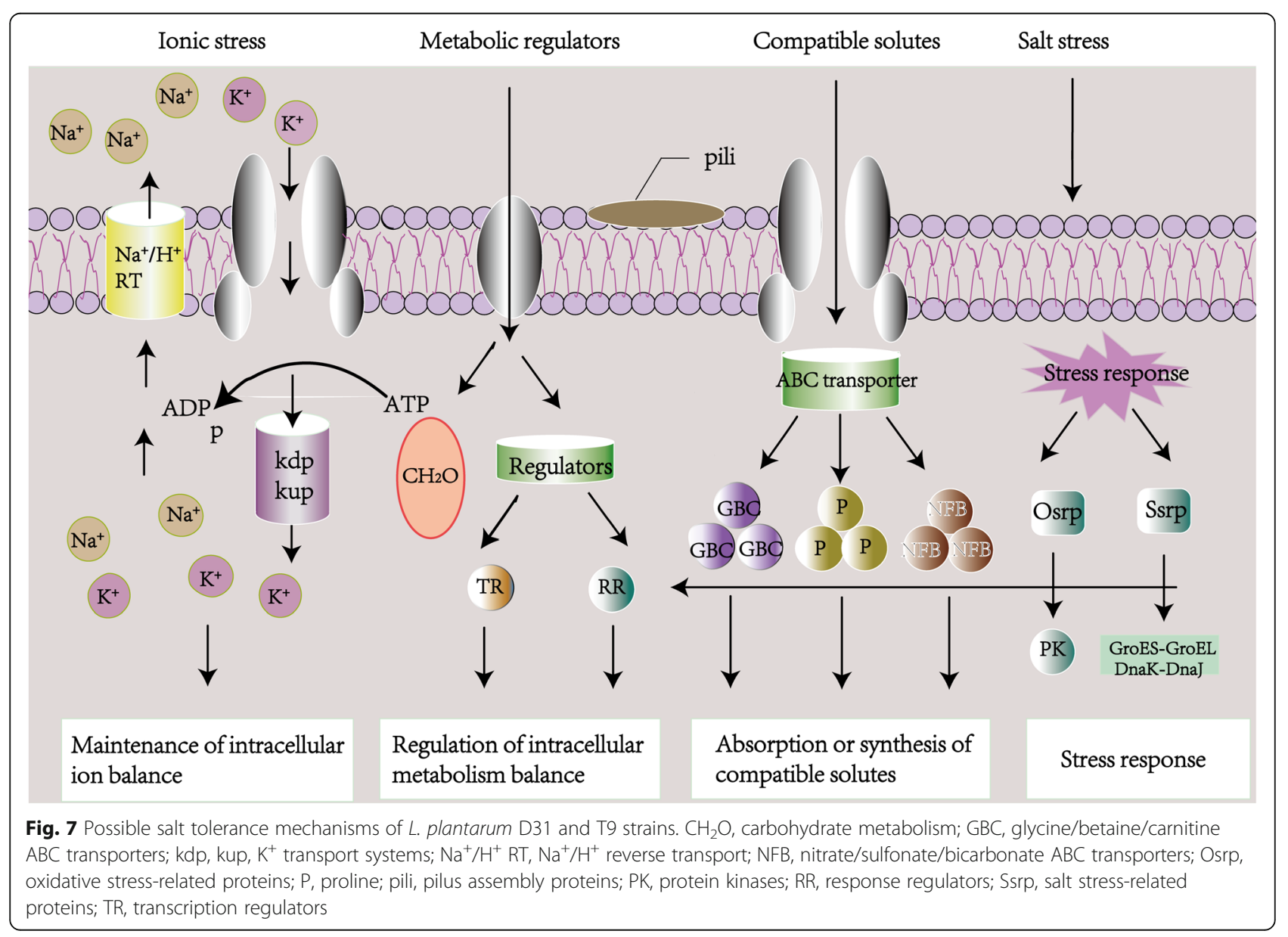


06450, D7Y66_02945), an elongation factor Tu (D7Y65 10495, D7Y66_10760), a glutamyl-tRNA synthase (D7Y65_14120, D7Y66_03390), a S-ribosylhomocysteine lyase (D7Y65_07140, D7Y66_03830), a malonyl CoA-acyl carrier protein transacylase (D7Y65_03550, D7Y66_ 02255), and a sigma-54 modulation protein (D7Y65 06955, D7Y66_03675) were also identified in L. plantarum D31 and T9 genomes, respectively. In addition, the gene encoding a carboxypeptidase was identified in L. plantarum D31 (D7Y65_13825) and ST-III, which shared 25\% amino acid sequence similarity with the protein (WP 010874021.1) directly or indirectly involved in salt sensing of Synechocystis sp. PCC 6803 (Huang et al. 2010).

Transcriptional profiles of salt resistance-associated genes in L. plantarum D31 and T9 strains

To couple the salt tolerance phenotypes of $L$. plantarum D31 and T9 strains with their salt resistance-associated genes identified by the comparative genomic analysis, we determined transcriptional profiles of 16 representative genes by the qRT-PCR assay. This analysis revealed many differentially expressed genes involved in the salt stress in the two strains (Figure S3, Fig. 6). For instance, when L. plantarum D31 was grown in $8 \% \mathrm{NaCl}$, the expression of the $k d p$ gene cluster and its regulators (D7Y65_15160 D7Y65_15165 D7Y65_15180) was remarkably upregulated (2.4-4.5 fold, $p<0.05)$, suggesting enhanced $\mathrm{K}^{+}$uptake of $L$. plantarum D31 cells in the stress condition. Likewise, when L. plantarum T9 stain incubated in $5 \% \mathrm{NaCl}$, the genes encoding the $\mathrm{Na}^{+} / \mathrm{H}^{+}$ antiporters (D7Y66_07525, D7Y66_13435) and cochaperone GroES and GroEL (D7Y66_03635, D7Y66_ 03640) showed higher transcriptional levels (changes $\geq$ 1.0-fold), implying increased antiporting of $\mathrm{Na}^{+} / \mathrm{H}^{+}$in $L$. plantarum T9 cells. Comparison of the transcriptional profiles revealed differentially expressed genes that were synchronously elicited from both L. plantarum D31 and T9 strains in the salt stress. Nevertheless, opposite transcriptional patterns were also observed in the two strains. For instance, the genes encoding the GroES and GroEL (D7Y65_06915, D7Y65_06920) were notably downregulated in L. plantarum D31 (0.14-0.33 fold, $p<$ 0.05). Additionally, Esteban-Torres et al. (2014) have reported a cold-active and salt-tolerant esterase from $L$. plantarum. In this study, the gene (lp_3505) encoding the esterase was also examined in L. plantarum D31 and T9 strains by the qRT-PCR assay. The resulting data showed that expression of the esterase gene was slightly reduced in $L$. plantarum D31 (0.32 fold, $p<0.05)$ and T9 (0.47 fold, $p<0.05)$ strains, respectively. These results suggested possible strain-specific regulatory mechanisms of $L$. plantarum in the salt stress.

Overall, both $L$. plantarum D31 and T9 strains were able to withstand high osmotic pressure caused by $5.0 \%$
$\mathrm{NaCl}$, and L. plantarum D31 even to tolerate $8.0 \% \mathrm{NaCl}$. Our genomic data, coupled with the previous studies, revealed a complex molecular regulatory network responding to the salt stress in L. plantarum (Fig. 7). The salt resistance-associated genes identified in $L$. plantarum D31 and L. plantarum T9 genomes fall into at least four distinct categories. One of these is involved in the recovery of intracellular ion balance, e.g., the $\mathrm{Na}^{+} / \mathrm{H}^{+}$reverse transport and $\mathrm{K}^{+}$transport systems. The genes encoding nitrate/sulfonate/bicarbonate $\mathrm{ABC}$ transporters and proline synthesis fall into the second category, which are likely essential for absorption or synthesis of compatible solutes. The third category may contain the genes involved in the regulation of intracellular metabolism balance, e.g., encoding transcriptional factors of GntR, TetR, Crp/Fnr, and LysR families, and a number of response regulators, particularly for the modulation of cell membrane composition changes. The genes involved in the stress response, e.g., encoding one-component regulatory systems DnaK-DnaJ and GroES-GroEL, may go into the fourth category (Fig. 7). The data in this study allowed us to better understand molecular coping strategies for the salt tolerance of $L$. plantarum. The bacterium with novel functional properties is of interest to both academic institution and food industry. Both L. plantarum D31 and T9 strains showing high level of salt tolerance are promising components for traditional food fermentations.

\section{Supplementary information}

Supplementary information accompanies this paper at https://doi.org/10. 1186/s13213-020-01551-2.

Additional file 1: Table S1. The genome features of the $50 \mathrm{~L}$. plantarum strains analyzed in this study.

Additional file 2: Table S2. The genes classified into 24 COG functional categories in L. plantarum D31 and T9 genomes.

Additional file 3: Table S3. Regulators related to the salt stress in $L$. plantarum D31 and T9 genomes.

Additional file 4: Figure S1. Agarose (0.7\%) gel electrophoresis analysis of genomic DNA extracted from L. plantarum D31 and T9 strains. (A): Lane 1: DNA molecular Maker: $\lambda /$ HindIII DNA Marker (Tiangen Biotech Co, Ltd., Beijing, China). Lane 2 and 3: genomic DNA samples extracted from L. plantarum D31 and T9 strains, respectively. Electrophoresis was performed at 120 voltage for about $30 \mathrm{~min}$ in $1 \times$ TAE buffer (Shanghai Sangon Biological Engineering Technology and Services Co., Ltd., Shanghai, China). (B): The marker ladder photo provided by the manufacturer.

Additional file 5: Figure S2. Agarose (1\%) gel electrophoresis analysis of total RNA extracted from L. plantarum D31 and T9 strains. Lane 1 and 3: L. plantarum D31 and T9 strains grown in MRS medium, respectively. Lane 2 and 4: L. plantarum D31 and T9 strains grown in MRS medium supplemented with $8 \%$, and $5 \% \mathrm{NaCl}$, respectively.

Additional file 6: Figure S3. Amplification plots of qRT-PCR products derived from the sixteen representative salt resistance-associated genes of L. plantarum D31 (A) and T9 (B) strains. The qRT-PCR assay was performed in a 7500 Fast Real-Time PCR System (Applied Biosystems, Foster City, CA, USA) (See Materials and methods). L. plantarum D31 and T9 strains grown in MRS medium supplemented with $8 \%$, and $5 \% \mathrm{NaCl}$, respectively. 


\section{Authors' contributions}

WY, LY, ZS, LX, and LC participated in the design and or discussion of the study. $W Y$, and LY carried out the major experiments and analyses. WY, and LC wrote the manuscript. All authors read and approved the final manuscript.

\section{Funding}

This work was supported by the grants from the Shanghai Municipal Science and Technology Commission (No. 17050502200) and the National Natural Science Foundation of China (No. 31671946).

\section{Ethics approval and consent to participate}

This article does not contain any studies with human participants or animals performed by any of the authors.

\section{Consent for publication}

Not applicable.

\section{Competing interests}

The authors declare that they have no competing interests.

\section{Author details}

${ }^{1}$ Key Laboratory of Quality and Safety Risk Assessment for Aquatic Products on Storage and Preservation (Shanghai), China Ministry of Agriculture, College of Food Science and Technology, Shanghai Ocean University, Shanghai 201306, People's Republic of China. ${ }^{2}$ Shanghai Center for Bioinformation Technology, Shanghai 201203, People's Republic of China.

\section{Received: 29 July 2019 Accepted: 29 January 2020}

\section{Published online: 03 March 2020}

\section{References}

Arsene F, Tomoyasu T, Bukau B (2000) The heat shock response of Escherichia coli. Int J Food Microbiol 55:3-9

Besemer J, Lomsadze A, Borodovsky M (2001) GeneMarkS: a self-training method for prediction of gene starts in microbial genomes. Implications for finding sequence motifs in regulatory regions. Nucleic Acids Res 29:2607-2618

Brown J, Pirrung M, McCue LA (2017) FQC Dashboard: integrates FastQC results into a web-based, interactive, and extensible FASTQ quality control tool. Bioinformatics 33:3137-3139. https://doi.org/10.1093/bioinformatics/btx373

Bucka-Kolendo J, Sokolowska B (2017) Lactic acid bacteria stress response to preservation processes in the beverage and juice industry. Acta Biochim Pol 64:459-464. https://doi.org/10.18388/abp.2017_1496

Chen C, Ai L, Zhou F, Ren J, Sun K, Zhang H, Chen W, Guo B (2012) Complete nucleotide sequence of plasmid pST-III from Lactobacillus plantarum ST-III. Plasmid 67:236-244 https://doi.org/10.1016/j.plasmid.2011.12.005

Chen L, Xu S, Pan Y. (2014) Diversity of lactic acid bacteria in Chinese traditional fermented foods. In: V Ravishankar Rai, Jamuna A. Bai (eds). Beneficial microbes in fermented and functional foods. CRC Press, London, pp3-14. https://doi.org/10.1201/b17912

Dahroud BD, Mokarram RR, Khiabani MS, Hamishehkar H, Bialvaei AZ, Yousefi M, Kafil HS (2016) Low intensity ultrasound increases the fermentation efficiency of Lactobacillus casei subsp.casei ATTC 39392. Int J Biol Macromol 86:462-467 https://doi.org/10.1016/j.ijbiomac.2016.01.103

Delcher AL, Bratke KA, Powers EC, Salzberg SL (2007) Identifying bacterial genes and endosymbiont DNA with Glimmer. Bioinformatics 23:673-679 https://doi. org/10.1093/bioinformatics/btm009

Edgar RC (2004) MUSCLE: multiple sequence alignment with high accuracy and high throughput. Nucleic Acids Res 32:1792-1797 https://doi.org/10.1093/ nar/gkh340

El-Gendy SM, Abdel-Galil H, Shahin Y, Hegazi FZ (1983) Characteristics of salttolerant lactic acid bacteria, in particular Lactobacilli, Leuconostocs and Pediococci, isolated from salted raw milk. J Food Prot 46:429-433. https://doi. org/10.4315/0362-028X-46.5.429

Epstein W (2003) The roles and regulation of potassium in bacteria. Prog Nucleic Acid Res Mol Biol 75:293 https://doi.org/10.1016/S0079-6603(03)75008-9

Esteban-Torres M, Mancheño JM, de las Rivas B, Muñoz R (2014) Characterization of a cold-active esterase from Lactobacillus plantarum suitable for food fermentations. J Agric Food Chem 62:5126-5132. https://doi.org/10.1021/ jf501493z
Evanovich E, de Souza Mendonca Mattos PJ, Guerreiro JF (2019) Comparative genomic analysis of Lactobacillus plantarum: an overview. Int J Genomics 2019:4973214. https://doi.org/10.1155/2019/4973214

Fu LM, Niu BF, Zhu ZW, Wu ST, Li WZ (2012) CD-HIT: accelerated for clustering the next-generation sequencing data. Bioinformatics 28:3150-3152 https:// doi.org/10.1093/bioinformatics/bts565

Glaasker E, Tjan FS, Ter Steeg PF, Konings WN, Poolman B (1998) Physiological response of Lactobacillus plantarum to salt and nonelectrolyte stress. J Bacteriol 180:4718-4723

Grissa I, Vergnaud G, Pourcel C (2007) CRISPRFinder: a web tool to identify clustered regularly interspaced short palindromic repeats. Nucleic Acids Res 35:52-57 https://doi.org/10.1093/nar/gkm360

Guindon S, Gascuel O (2003) A simple, fast, and accurate algorithm to estimate large phylogenies by maximum likelihood. Syst Biol 52:696 https://doi.org/10 1080/10635150390235520

Gupta SK, Padmanabhan BR, Diene SM, Lopez-Rojas R, Kempf M, Landraud L, Rolain JM (2014) ARG-ANNOT, a new bioinformatic tool to discover antibiotic resistance genes in bacterial genomes. Antimicrob Agents Chemoter 58:212220 https://doi.org/10.1128/AAC.01310-13

Hamon E, Horvatovich P, Izquierdo E, Bringel F, Marchioni E, Aoude-Werner D, Ennahar S (2011) Comparative proteomic analysis of Lactobacillus plantarum for the identification of key proteins in bile tolerance. BMC Microbiol 11:63. https://doi.org/10.1186/1471-2180-11-63

Heermann R, Weber A, Mayer B, Ott M, Hauser E, Gabriel G, Pirch T, Jung K (2009) The universal stress protein UspC scaffolds the $\mathrm{KdpD} / \mathrm{KdpE}$ signaling cascade of Escherichia coli under salt stress. J Mol Biol 386:134-148 https://doi.org/10. 1016/j.jmb.2008.12.007

Huang F, Fulda S, Hagemann M, Norling B (2010) Proteomic screening of saltstress-induced changes in plasma membranes of Synechocystis sp. strain PCC 6803. Proteomics 6:910-920 https://doi.org/10.1002/pmic.200500114

Huang R, Pan M, Wan C, Shah NP, Tao X, Wei H (2016) Physiological and transcriptional responses and cross protection of Lactobacillus plantarum ZDY2013 under acid stress. J Dairy Sci 99:1002-1010. https://doi.org/10.3168/jds.2015-9993

Jia FF, Zheng HQ, Sun SR, Pang XH, Liang Y, Shang JC, Zhu ZT, Meng XC. (2018) Role of luxS in stress tolerance and adhesion ability in Lactobacillus plantarum KLDS1.0391. Biomed Res Int 2018:4506829. https://doi:https://doi. org/10.1155/2018/4506829

Jiang Y, Zhang J, Zhao X, Zhao W, Yu Z, Chen C, Yang Z (2018) Complete genome sequencing of exopolysaccharide-producing Lactobacillus plantarum K25 provides genetic evidence for the probiotic functionality and cold endurance capacity of the strain. Biosci Biotechnol Biochem 82:1225-1233. https://doi.org/10.1080/09168451.2018.1453293

Kang MS, Okuyama M, Mori H, Kimura A (2009) The first alpha-1,3-glucosidase from bacterial origin belonging to glycoside hydrolase family 31. Biochimie 91:1434-1442 https://doi.org/10.1016/j.biochi.2009.07.018

Kido EA, Ferreira Neto JR, Silva RL, Belarmino LC, Bezerra NJP, Soares-Cavalcanti NM, Pandolfi V, Silva MD, Nepomuceno AL, Benko-Iseppon AM. (2013) Expression dynamics and genome distribution of osmoprotectants in soybean: identifying important components to face abiotic stress. BMC Bioinformatics 14 Suppl 1:S7. https://doi.org/10.1186/1471-2105-14-S1-S7

Kleerebezem M, Boekhorst J, van Kranenburg R, Molenaar D, Kuipers OP, Leer R et al (2003) Complete genome sequence of Lactobacillus plantarum WCFS1. Proc Natl Acad Sci U S A 100:1990-1995 https://doi.org/10.1073/pnas.0337704100

Krogh A, Larsson B, von Heijne G, Sonnhammer EL (2001) Predicting transmembrane protein topology with a hidden Markov model: application to complete genomes. J Mol Biol 305:567-580 https://doi.org/10.1006/jmbi. 2000.4315

Lagesen K, Hallin P, Rodland EA, Staerfeldt HH, Rognes T, Ussery DW (2007) RNAmmer: consistent and rapid annotation of ribosomal RNA genes. Nucleic Acids Res 35:3100-3108 https://doi.org/10.1093/nar/gkm160

Lee KW, Park JY, Sa HD, Jeong JH, Jin DE, Heo HJ, Kim JH (2014) Probiotic properties of Pediococcus strains isolated from jeotgals, salted and fermented Korean seafood. Anaerobe 28:199-206 https://doi.org/10.1016/j.anaerobe.2014.06.013

Li P, Gu Q, Yang L, Yu Y, Wang Y (2017) Characterization of extracellular vitamin B12 producing Lactobacillus plantarum strains and assessment of the probiotic potentials. Food Chem 234:494-501 https://doi.org/10.1016/j. foodchem.2017.05.037

Liu CJ, Wang R, Gong FM, Liu XF, Zheng HJ, Luo YY, Li XR (2015) Complete genome sequences and comparative genome analysis of Lactobacillus plantarum strain 5-2 isolated from fermented soybean. Genomics 106:404411 https://doi.org/10.1016/j.ygeno.2015.07.007 
Liu Y, Alookaran JJ, Rhoads JM (2018) Probiotics in autoimmune and inflammatory disorders. Nutrients 10:1537 https://doi.org/10.3390/ nu10101537

Livak KJ, Schmittgen TD. (2001). Analysis of relative gene expression data using real-time quantitative PCR and the 2(-delta delta C(T)) method. Methods (San Diego, Calif) 25, 402-408. https://doi.org/10.1006/meth.2001.1262

Lowe TM, Eddy SR (1997) tRNAscan-SE: a program for improved detection of transfer RNA genes in genomic sequence. Nucleic Acids Res 25:955-964 https://doi.org/10.1093/nar/25.5.955

Mahan MJ, Csonka LN (1983) Genetic analysis of the proBA genes of Salmonella typhimurium: physical and genetic analyses of the cloned $p r o B^{+} A^{+}$genes of Escherichia coli and of a mutant allele that confers proline overproduction and enhanced osmotolerance. J Bacteriol 156:1249-1262

Marchler-Bauer A, Derbyshire MK, Gonzales NR, Lu S, Chitsaz F, Geer LY et al (2015) CDD: NCBI's conserved domain database. Nucleic Acids Res 43:D222D226 https://doi.org/10.1093/nar/gku1221

Molin G. (2001) Probiotics in foods not containing milk or milk constituents, with special reference to Lactobacillus plantarum 299v. Am J Clin Nutr 73:380 s385 s. https://doi.org/10.1093/ajcn/73.2.380s

Nazir Y, Hussain SA, Abdul Hamid A, Song Y (2018) Probiotics and their potential preventive and therapeutic role for cancer, high serum cholesterol, and allergic and HIV diseases. Biomed Res Int 2018:3428437 https://doi.org/10. $1155 / 2018 / 3428437$

Nyanga-Koumou AP, Ouoba LI, Kobawila SC, Louembe D (2012) Response mechanisms of lactic acid bacteria to alkaline environments: a review. Crit Rev Microbiol 38:185 https://doi.org/10.3109/1040841X.2011.640978

Oshone R, Ngom M, Chu F, Mansour S, Sy MO, Champion A, Tisa LS (2017) Genomic, transcriptomic, and proteomic approaches towards understanding the molecular mechanisms of salt tolerance in Frankia strains isolated from Casuarina trees. BMC Genomics 18:633 https://doi.org/10.1186/s12864-0174056-0

Padan E, Bibi E, Ito M, Krulwich TA (2005) Alkaline pH homeostasis in bacteria: new insights. Biochim Biophys Acta 1717:67-88 https://doi.org/10.1016/j. bbamem.2005.09.010

Peddie BA, Lever M, Hayman CM, Randall K, Chambers ST (1994) Relationship between osmoprotection and the structure and intracellular accumulation of betaines by Escherichia coli. FEMS Microbiol Lett 120:125-131 https://doi.org/ 10.1111/j.1574-6968.1994.tb07018.x

Petersen TN, Brunak S, von Heijne G, Nielsen H (2011) SignalP 4.0: discriminating signal peptides from transmembrane regions. Nat Methods 8:785-786

Piuri M, Sanchez-Rivas C, Ruzal S (2010) Cell wall modifications during osmotic stress in Lactobacillus casei. J Appl Microbiol 98:84-95 https://doi.org/10. 1111/j.1365-2672.2004.02428.x

Prasad J, McJarrow P, Gopal P (2003) Heat and osmotic stress responses of probiotic Lactobacillus rhamnosus HN001 (DR20) in relation to viability after drying. Appl Environ Microbiol 69:917-925 https://doi.org/10.1128/aem.69.2. 917-925.2003

Qin YJ, Huang ZQ, Liu ZD (2014) A novel cold-active and salt-tolerant alphaamylase from marine bacterium Zunongwangia profunda: molecular cloning, heterologous expression and biochemical characterization. Extremophiles 18 : 271-281 https://doi.org/10.1007/s00792-013-0614-9

Ramos JL, Martínezbueno M, Molinahenares AJ, Terán W, Watanabe K, Zhang X, Gallegos MT, Brennan R, Tobes R (2005) The TetR family of transcriptional repressors. Microbiol Mol Biol Rev 69:326-356 https://doi.org/10.1128/MMBR. 69.2.326-356.2005

Rao MS, Pintado J, Stevens WF, Guyot JP (2004) Kinetic growth parameters of different amylolytic and non-amylolytic Lactobacillus strains under various salt and pH conditions. Bioresour Technol 94:331-337. https://doi.org/10. 1016/j.biortech.2003.11.028

Shehata MG, El Sohaimy SA, El-Sahn MA, Youssef MM (2016) Screening of isolated potential probiotic lactic acid bacteria for cholesterol lowering property and bile salt hydrolase activity. Ann Agric Sci 61:65-75 https://doi. org/10.1016/j.aoas.2016.03.001

Siezen RJ, van Hylckama Vlieg JE (2011) Genomic diversity and versatility of Lactobacillus plantarum, a natural metabolic engineer. Microb Cell Factories 10(Suppl 1):S3. https://doi.org/10.1186/1475-2859-10-S1-S3

Sugimoto S, Saruwatari K, Higashi C, Tsuruno K, Matsumoto S, Nakayama J, Sonomoto K (2008) In vivo and in vitro complementation study comparing the function of DnaK chaperone systems from halophilic lactic acid bacterium Tetragenococcus halophilus and Escherichia coli. Biosci Biotechnol Biochem 72:811-822 https://doi.org/10.1271/bbb.70691
Sun X, Liu T, Xu P, Chen L (2014) Insights into Vibrio parahaemolyticus CHN25 response to artificial gastric fluid stress by transcriptomic analysis. Int J Mol Sci 15:22539-22562 https://doi.org/10.3390/ijms151222539

Tatusov RL, Natale DA, Garkavtsev IV, Tatusova TA, Shankavaram U, Rao BS, Kiryutin B, Galperin MY, Fedorova ND, Koonin EV (2001) The COG database: new developments in phylogenetic classification of proteins from complete genomes. Nucleic Acids Res 29:22-28 https://doi.org/10.1093/nar/29.1.22

Vasyliuk OM, Kovalenko NK, Harmasheva IL (2014) Physiological and biochemical properties of the Lactobacillus plantarum, isolated from traditional fermented products of Ukraine. Mikrobiol Z 76:2-8

Wang PP, Wu Z, Wu J, Pan D, Zeng XQ, Cheng KM (2016) Effects of salt stress on carbohydrate metabolism of Lactobacillus plantarum ATCC 14917. Curr Microbiol 73:1-7 https://doi.org/10.1007/s00284-016-1087-8

Xin XU, Wang QQ, Wang XR, Xue YT, Ri-Na WU (2014) Isolation and identification of salt-resistant lactic acid bacteria in farmers' soybean paste. Food Ferment Ind 40:33-40

Xu S, Liu T, Radji CA, Yang J, Chen L (2016) Isolation, identification, and evaluation of new lactic acid bacteria strains with both cellular antioxidant and bile salt hydrolase activities in vitro. J Food Prot 79:1919-1928 https:// doi.org/10.4315/0362-028X.JFP-16-096

Yamani MI, Alnabulsi AA, Haddadin MS, Robinson RK (1998) The isolation of salttolerant lactic acid bacteria from ovine and bovine milks for use in the production of nabulsi cheese. Int J Dairy Technol 51:86-89 https://doi.org/10. 1111/j.1471-0307.1998.tb02643.x

Zago M, Fornasari ME, Carminati D, Burns P, Suarez V, Vinderola G, Reinheimer J, Giraffa G (2011) Characterization and probiotic potential of Lactobacillus plantarum strains isolated from cheeses. Food Microbiol 28:1033-1040 https://doi.org/10.1016/j.fm.2011.02.009

Zakharyan E, Trchounian A (2001) $\mathrm{K}^{+}$influx by Kup in Escherichia coli is accompanied by a decrease in $\mathrm{H}^{+}$efflux. FEMS Microbiol Lett 204:61-64 https://doi.org/10.1111/j.1574-6968.2001.tb10863.x

Zhang B, Wang Y, Tan Z, Li Z, Jiao Z, Huang Q (2016) Screening of probiotic activities of Lactobacilli strains isolated from traditional Tibetan Qula, a raw yak milk cheese. Asian Austral J Anim 29:1490-1499 https://doi.org/10.5713/ ajas. 15.0849

Zhang H, Gao S, Lercher MJ, Hu S, Chen WH (2012) EvolView, an online tool for visualizing, annotating and managing phylogenetic trees. Nucleic Acids Res 40:569-572 https://doi.org/10.1093/nar/gks576

Zhu C, Sun B, Liu T, Zheng H, Gu W, He W, Sun F, Wang Y, Yang M, Bei W, Peng X, She Q, Xie L, Chen L (2017) Genomic and transcriptomic analyses reveal distinct biological functions for cold shock proteins (VpaCspA and VpaCspD) in Vibrio parahaemolyticus CHN25 during low-temperature survival. BMC Genomics 18:436 https://doi.org/10.1186/s12864-017-3784-5

\section{Publisher's Note}

Springer Nature remains neutral with regard to jurisdictional claims in published maps and institutional affiliations.

Ready to submit your research? Choose BMC and benefit from:

- fast, convenient online submission

- thorough peer review by experienced researchers in your field

- rapid publication on acceptance

- support for research data, including large and complex data types

- gold Open Access which fosters wider collaboration and increased citations

- maximum visibility for your research: over $100 \mathrm{M}$ website views per year

At $\mathrm{BMC}$, research is always in progress.

Learn more biomedcentral.com/submissions 